\title{
SOCIOLOGIA NO ENSINO MÉDIO EM UM MUNDO EM MUDANÇAS: A QUESTÃO DA “CONFLUÊNCIA PERVERSA"
}

\author{
Doraci Alves Lopes \\ Dulce Maria Pompêo de Camargo* \\ Rafael Fernando da Costa ${ }^{* * *}$
}

\begin{abstract}
RESUMO: Este artigo apresenta uma reflexão sobre Oficinas Pedagógicas de Sociologia oferecidas mensalmente para a formação continuada de professores de ensino médio da escola pública, bem como para a formação de licenciados de Ciências Sociais pelo Laboratório de Ensino, Sociedade e Cultura (LESC) da PUC-Campinas (1998-2007). O conceito de "confluência perversa" permitiu-nos repensar as oficinas em meio à disputa entre o projeto político democrático e o projeto político neoliberal, uma vez que a educação e a escola passaram, desde o início de 1990, por transformaçōes que atingiram as relaçôes de trabalho docente, cada vez mais fragmentado e desregulamentado. E mais, além da implantação de avaliaçōes de larga escala com criação de rankings entre as escolas públicas, estas passaram a ser disputadas por projetos de educação não formal da sociedade civil, em "parcerias" pouco preocupadas com uma discussão democrática interna para se adequarem à realidade concreta das escolas. Tais desafios, ao nosso entender, são um dos núcleos de atuação da "confluência perversa" no país, pouco percebida naqueles anos de LESC e talvez até nos dias de hoje.
\end{abstract}

Palavras-chave: Formação de professores. Sociologia. Ensino médio. Confluência perversa.

* Doutora em Sociologia e professora aposentada da Faculdade de Ciências Sociais da Pontifícia Universidade Católica de Campinas (PUC-Campinas).E-mail: doraci.lopes@gmail.com

** Doutora em Educação e professora aposentada do Programa de Pós-Graduação em Educação da PUC-Campinas e da Universidade Estadual de Campinas (UNICAMP). E-mail: dpompeo@mpc.com.br

*** Mestre em Educação e professor do Programa de Formação de Professores da Educação Básica (PARFOR - PUC-Campinas). E-mail: rafaelich@ig.com.br 
Sociologia no ensino médio em um mundo em mudanças...

\title{
SOCIOLOGY IN HIGH SCHOOL IN A CHANGING WORLD: QUESTION OF PERVERSE CONFLUENCE
}

\begin{abstract}
This article presents a reflection on the Sociology Pedagogical Workshops offered monthly for the continuing formation of high school teachers of public schools, as well as for the formation of teachers certified in Social Sciences by the Laboratory of Teaching Society and Culture (LESC, PUC-Campinas - 19982007). The concept of 'perverse confluence' allowed us to rethink the workshops through the dispute between the democratic and neoliberal political projects, once school and education have, since the beginning of 1990, undergone transformation that have reached academician relations, increasingly fragmented and deregulated. In addition, besides the implementation of large-scale assessments with a ranking among public schools, these started to be disputed by civil society's projects of non-formal education in 'partnerships' little concerned with an internal democratic discussion aiming to adapt to the concrete reality of schools. Such challenges as far we can judge, are one of the manifestation focuses of 'perverse confluence' in the country, hardly noticed during those LESC years and perhaps even today.
\end{abstract}

Key words: Education of teachers. Sociology. High school. Perverse confluence.

\section{Introdução}

\section{7 intenção desta reflexão é analisar uma experiência de Oficinas Pedagógicas desenvolvida no Laboratório de Ensino, Sociedade e Cultura (LESC) entre os anos de 1998 e 2007, na PUC-Campi-} nas, a partir da discussão da "confluência perversa". A ideia de se retomar este processo é parte de um compromisso maior de um conjunto de docentes motivados em discutir os caminhos da Sociologia no ensino médio no Brasil, marcados por alternâncias curriculares difíceis, às vezes autoritárias. $\mathrm{O}$ artigo pretende explicitar uma leitura a posteriori do trabalho no LESC com a expectativa de encontrar e trocar novos olhares, de enriquecer a continuidade desta reflexão sobre a Sociologia no ensino médio.

O objetivo principal das oficinas era o de intensificar a formação inicial dos licenciandos das Ciências Sociais da PUC-Campinas em 
conjunto com a formação continuada para professores de Sociologia de escolas públicas de Campinas, combinando atividades de ensino, pesquisa e extensão universitária.

Inicialmente, faremos uma introdução histórica e teórica do debate da "confluência perversa" que permeia a análise para, em seguida, dialogar com outros autores representativos das Ciências Sociais e da educação que nos auxiliam a situar a Sociologia em determinadas questôes sobre o ensino médio, especialmente na década de 1990 - período de intensas mudanças econômicas, políticas e sociais no modo de produção capitalista mundial, atingindo diretamente a educação, inclusive no Brasil.

Posteriormente, apresentamos um balanço e o detalhamento sobre a experiência das Oficinas Pedagógicas de Sociologia do LESC levando em conta pelo menos dois desafios enfrentados na realização destas: a histórica lacuna da disciplina Sociologia no universo curricular do ensino médio; o peso das mudanças em curso na educação em razão da influência do mercado perante a competitividade nacional e internacional exigida pela economia global; e outros desafios mais locais, como a não dispensa mensal dos professores da rede pública pelas escolas, dificultando a formação continuada nas oficinas.

A parte final é uma tentativa de contar o estranhamento vivido pela equipe responsável com relação aos deslocamentos conceituais encontrados nos materiais didáticos apresentados, principalmente pelos professores da rede pública, e não compreendidos naquela época. Estranhamentos certamente não inteiramente desvendados ainda por esta análise, o que pode provocar certas dúvidas também no leitor. Mas esperamos que estas dificuldades possam se transformar em uma nova fase de reflexão coletiva e propiciem maior clareza para propormos caminhos mais consistentes e duradouros para a Sociologia no ensino médio.

O esforço é localizar este balanço também no contexto das transformaçóes da sociedade civil, do Estado e de projetos políticos em disputa no país. A referida época foi um momento de criação de novos "experimentos" de participação democrática no espaço público e, ao mesmo tempo, momento de defesa dos processos de privatização das políticas públicas (Dagnino, 2006). É preciso reconhecer ainda a existência da vertente de um pensamento autoritário que disputa 
igualmente um lugar no espaço público, continuamente saudoso de um Estado que se considera "demiurgo" da sociedade (Ianni, 2000).

A perspectiva teórica que embasa a discussão desta experiência é dada pela preocupação com certos deslocamentos conceituais de termos caros ao pensamento das ciências humanas, como os de cidadania, democracia, sociedade civil, participação política, entre outros. Debate que tem sido aprofundado por diferentes autores das Ciências Sociais e da educação. Destacamos em especial as análises de Evelina Dagnino centradas na problematização das relaçõos entre Estado e sociedade civil e suas complexas transformações nas últimas décadas do século XX, a partir de um amplo conjunto de pesquisas empíricas, com a participação de representativos estudiosos brasileiros e latino-americanos. A autora defende que é no campo das "experiências" de projetos políticos que se pode afirmar a existência de uma renovação do debate sobre a democracia, seus avanços, possibilidades e limites. Como também explicita os complexos e heterogêneos "trânsitos" entre as esferas da sociedade política e da sociedade civil, uma vez que esses estudos rejeitam a visão tradicional de uma "dicotomia" entre uma e outra esfera no campo das lutas políticas (Dagnino, 2006).

Repensando as Oficinas Pedagógicas de Sociologia do LESC e os desafios do ensino médio

A partir dos processos vivenciados na licenciatura de Sociologia, temos refletido acerca do distanciamento entre a cultura do ensinar e a realidade concreta de professores e alunos de Sociologia em um contexto histórico de rápidas e intensas transformações nas várias dimensōes da vida social, especialmente marcadas pela hegemonia do projeto neoliberal em amplas esferas da vida social desde as últimas décadas do século XX.

Acreditamos que um dos grandes problemas vivenciados na licenciatura de Sociologia é o desencontro pouco visível entre projetos políticos, interesses, culturas e visões de mundo, seja no universo de formação docente, seja na experiência posterior, como professores. Tendo em vista o contexto histórico em que as oficinas do LESC ocorreram, tentaremos interpretar esta experiência a partir da discussão da formação inicial e continuada de professores de Sociologia com base no conceito de confluência perversa, conforme Dagnino (2005). 
Segundo a autora, o grande desafio é discutir a "apropriação e resignificação de referências caras ao projeto democrático que, redefinidas, passam a abrigar significados fundamentais do projeto neoliberal" (op. cit., p. 45), principalmente a partir da década de 1990. Dagnino (2005) afirma que essa apropriação gera uma crise discursiva e destaca três referências importantes neste processo de re-significação: as noçôes de sociedade civil, participação e cidadania. Tal processo obscurece as diferenças entre estes dois projetos políticos, necessitando ser enfrentado pelo que denomina de uma agenda intelectual, cultural e política (p. 61). Proposta com a qual nos identificamos e tomamos como desafio para repensarmos a realidade da Sociologia no ensino médio.

Nesta experiência, no LESC da PUC-Campinas (1998-2007), a "confluência perversa" e a "crise discursiva" perpassavam nossa dificuldade de compreender as ambiguidades que permeavam o processo de formação inicial e a continuada, de professores de Sociologia da rede oficial de ensino que atuam na Região Metropolitana de Campinas. A interpretação realizada deste processo trouxe uma série de indagaçôes. Como tornar visíveis as diferenças entre o projeto político democrático e o projeto político neoliberal, mais especificamente no ensino de Sociologia? Qual a particularidade do ensino de Sociologia no projeto democrático, uma vez que não é suficiente nos referirmos a determinados conceitos fundantes como os de cidadania, participação e sociedade civil, dadas suas re-significaçōes? Enfim, como superar a "crise discursiva" que atinge também o ensino e a formação de professores de Sociologia?

A seguir, procuramos analisar também os Cadernos de Sociologia do governo do estado de São Paulo na mesma perspectiva teórica, no sentido de apontar algumas práticas de ensino a partir de um programa de ensino oficial mais recente na rede de ensino. A ideia foi contribuir para a oportuna proposta apresentada pelo Centro de Estudos Educação e Sociedade (CEDES) para pensarmos o lugar da Sociologia no ensino médio.

O trabalho que desenvolvemos no grupo de pesquisa LESC incluía atividades ligadas a ensino, pesquisa e extensão, por cerca de nove anos, e tinha como preocupação central a formação inicial de licenciados e a continuada de professores de Sociologia da rede oficial de ensino da Região Metropolitana de Campinas. O objetivo central 
foi o de contribuir para a autonomia e a emancipação intelectual da prática docente por intermédio de conteúdos temáticos levantados durante as oficinas.

Nesse caminhar, os diferentes conhecimentos, ao serem construídos, foram a cada passo abrindo novas frentes, novas necessidades, novos objetos de estudo. A experiência que ora relatamos é parte de um longo processo de luta, que extrapola a temporalidade do LESC, e no qual nos inserimos a partir de 1984. A busca foi para a ampliação e manutenção de um espaço para a disciplina Sociologia no currículo escolar do ensino médio em Campinas e região, antes mesmo da conquista pela sua obrigatoriedade (Lei Federal n. 11.684/08).

Nesse processo, atualizávamos constantemente o mapeamento das escolas de ensino médio que adotavam a disciplina, ampliando o acervo bibliográfico sobre temas fundamentais e, nas Oficinas Pedagógicas oferecidas mensalmente aos professores da rede, dávamos continuidade à discussão teórico-metodológica dos conteúdos a serem trabalhados por eles. Tais procedimentos, aliados ao acompanhamento da legislação pertinente, foram fundamentais para o desenvolvimento e a finalização deste projeto político-pedagógico da licenciatura da Faculdade de Ciências Sociais da PUC-Campinas.

Com base nas rápidas mudanças mencionadas, tanto na sociedade como também no mundo do trabalho, enfrentamos exigências para a construção de novos processos político-pedagógicos para a formação inicial e continuada de professores que permitissem outras formas de leituras, relações, conexões entre os conhecimentos e a interpretação da realidade aliada à ação educacional.

Tal perspectiva implicava a recuperação do espírito de ciência como construção social permanente, uma vez que o conhecimento científico está estreitamente vinculado às condições reais e materiais, em época e contextos sociais determinados.

Nesse processo a Sociologia, cada vez mais, deve ser pensada como uma ciência que se interroga de novo sobre sua especificidade diante de outras áreas de conhecimento. $\mathrm{O}$ fato de a obrigatoriedade da Sociologia no ensino médio só ter sido conquistada recentemente torna a tarefa da docência muito mais complexa, dadas as contradições e tensões permanentes vivenciadas em uma sociedade profundamente marcada por mudanças de valores sociais e éticos. 
Comparado com os idos de 1960, o panorama atual da Sociologia exibe uma complexidade desconcertante, aqui e pelo mundo afora. Sua marca mais evidente é a diversidade. (...) Daí a importância, no seu programa [Conferência X Congresso Brasileiro de Sociologia, 2001], dos temas emergentes. (...) Pensar a Sociologia a sério é pensar a sociedade; mas pensar a sociedade ainda não é pensar a Sociologia. Cumpre, portanto, à Sociologia manter vivo seu autoquestionamento (...) para descobrir os seus potenciais e, neles, as novas dimensões da sociedade que lhe cabe introduzir nos seus esquemas analíticos. (...) a Sociologia perdeu terreno, a ponto de continuar sendo uma tarefa premente a definição e a implementação do ensino da Sociologia nos currículos de Segundo Grau (tema sobre o qual a Assembleia deste congresso certamente se manifestará). (Cohn, 2003, p. 83-84)

A par da discussão do papel da Sociologia como ciência e como formação inicial e continuada de docentes, tentamos pensar sobre o significado da dimensão social da escola e da construção de alternativas pedagógicas que possibilitassem ao aluno compreender e transformar o mundo. Neste contexto o ensino médio parece ser o mais prejudicado, tanto pela falta de investimentos a ele destinados como pela falta de uma política que permita atender minimamente às expectativas e aspirações de alunos e professores.

Apesar dos esforços em vários campos da educação para alcançar uma mudança no ensino médio nos aspectos humano e material, que considere prioritária a formação de cidadãos participantes, transformadores, continua sendo difícil romper com a exclusiva preocupação de colocar mão de obra à disposição do mercado de trabalho, projeto político caro aos interesses do mercado.

O currículo do ensino médio também precisa ser reformado, disse Magalhães, que é presidente do Instituto de Co-Responsabilidade pela Educação (ICE). "Temos de repensar a grade". Para ele, só deveriam ser obrigatórias as disciplinas de português e língua estrangeira, além de matemática, física, química e biologia. As outras matérias seriam eletivas. "Hoje o aluno que vai prestar vestibular para engenharia perde tempo estudando filosofia. Se ele achar importante, deveria ter a opção de cursála, não a obrigação". (Lordelo, 2011; grifo nosso)

Para tanto, a escola necessita encontrar meios para resistir, ter criatividade e autonomia e, principalmente, se propor a elaborar o seu próprio projeto político democrático, portanto com a participação da 
Sociologia no ensino médio em um mundo em mudanças...

comunidade escolar. É nesse bojo que se situa a discussão e o redimensionamento da concepção de currículo, entre outras questões a serem repensadas no ensino médio.

(...) alguns colégios particulares decidiram fazer lobby para desbastar os currículos. A ideia é que as novas disciplinas sejam lecionadas como parte das disciplinas básicas (...). Em São Paulo, por exemplo, o Conselho Estadual de Educação acaba de emitir um parecer permitindo que os conteúdos de filosofia e sociologia sejam dados dentro de outras disciplinas - como história. É um exemplo a ser seguido pelos outros estados. ( $O$ Estado de S. Paulo, 2010, p. A3)

Moraes (1996, p. 124) chama a atenção para o fato de o ensino médio ser talvez o mais problematizado na história da educação brasileira, uma vez que "historicamente manifesta o nó da relação social implícita no ensino escolar nacional”. Em síntese, a política educacional para o ensino médio tem se baseado fundamentalmente na "teoria do capital humano", que privilegia a produção em detrimento da formação do cidadão autônomo e criativo. Com um empobrecimento social dos currículos e o esvaziamento dos conteúdos voltados à formação geral, são descartadas as bases fundamentais para a compreensão crítica da realidade pelo educando.

Tais transformações acabaram por desestabilizar no campo educacional o rigor científico, o qual, como processo instituído, considerava eficaz a transmissão do conhecimento. Nesta perspectiva, há uma transformação considerável tanto na concepção de ciência como de ensino, que passam a exigir novas metodologias no processo de ensino e aprendizagem em razão das estratégias globais de desenvolvimento econômico contemporâneo. Essas mudanças estão sendo pensadas em uma realidade de disputas entre dois projetos políticos, o neoliberal e o democrático participativo. Este último implica combater a visão hegemônica da racionalidade técnica nas escolas:

O modelo de racionalidade técnica apesar de ser muito questionado ainda se encontra presente na organização curricular dos cursos de formação de professores e também introjetado na concepção dos licenciandos sobre a formação de professores que, mesmo de forma crítica, expõe uma visão do papel do professor como o possuidor do saber que deve "aplicar" aos alunos do ensino médio o conhecimento aprendido na teoria. (Costa, 2009, p. 110) 
O quadro atual, como vemos, bastante controvertido, traduz perspectivas pouco nítidas e duvidosas, preservando a velha trama de indefinições e dubiedades para o ensino médio e profissional que precisam ser mais bem entendidas e estudadas (Bueno, 2000).

Em São Paulo, a inserção da Sociologia no currículo dependia, e, como vimos, ainda depende, da "boa vontade" de diretores, coordenadores pedagógicos e dos demais envolvidos na elaboração do currículo escolar, gerando uma tensão nos professores a cada novo ano letivo. Isso sem considerar a falta de tradição da disciplina no contexto curricular do ensino médio, no trabalho do LESC; mesmo assim buscamos alternativas para resistir à hegemonia da racionalidade técnica.

A construção de conhecimento justifica a opção por uma metodologia de trabalho, onde o "ir e vir" permita a abordagem integrada do conteúdo trabalhado com o mundo percebido pelo aluno. Além de evitar a fragmentação do conhecimento, respeita as diferentes formas de ver e ler a realidade, próprias de professores e de alunos de camadas sociais e culturais distintas. (Camargo, 2000, p. 219)

(...) [vivemos] certos processos e modelos cientificistas, como os da hierarquização do saber, que selecionam que educadores valem mais e que educadores valem menos... É possível interromper essa dinâmica educacional social estúpida, que cria desigualdades inaceitáveis no reconhecimento institucional entre os graduados/licenciados nas diversas áreas das ciências, e também no interior das ciências humanas? (Lopes, 2001)

(...) Tão importante é esta integração entre a universidade e a escola pública (...) foram valiosíssimas as reflexôes sobre a LDB/96, sobre o papel da Sociologia no ensino médio, as ciências humanas e suas tecnologias, os Parâmetros Curriculares Nacionais, entre outros assuntos igualmente importantes... É urgente a união de todas as forças para o resgate do valor das Ciências Sociais na educação e na sociedade... (Professora de Sociologia, 2004)

Portanto, a criação e avaliação das concepções que permeavam o cotidiano escolar e a elaboração e utilização de materiais de ensino constituíam, no Laboratório, um campo fértil para que pudéssemos refletir acerca dos problemas relativos ao ensino e à aprendizagem, no curso de Ciências Sociais. Nesse processo a participação de professores da rede oficial de ensino nas oficinas mensais foi de fundamental importância. Em suma, o LESC teve por objetivos: 
Sociologia no ensino médio em um mundo em mudanças...

- Estreitar a cooperação entre o corpo docente e discente nas atividades de ensino, pesquisa e extensão;

- Contribuir para as atividades de estágios desenvolvidos por nossos alunos, nas escolas da rede oficial de ensino;

- Incentivar e apoiar, em nível de graduação, o desenvolvimento de pesquisas científicas na área de educação, contribuindo para a consolidação de sua formação;

- Contribuir para a formação profissional do professor do ensino médio, por intermédio de novas metodologias de ação em sala de aula e conteúdo específico da área (Projeto de Pesquisa e Extensão "Laboratório de Ensino, Sociedade e Cultura”, PUC-Campinas). (Camargo, 1997)

Tais oficinas, realizadas aos sábados, das 8 às 11 horas, abordavam diferentes temas entre os quais destacamos: "cidadania", "movimentos sociais" e "cultura”, e se constituíram em uma experiência ímpar para todos. Os registros das atividades desenvolvidas e dos depoimentos de professores e alunos da Faculdade de Ciências Sociais e do ensino médio oficial se deram por meio de fotos, filmagem e registro no diário de campo. A frequência de professores de Sociologia nas Oficinas Pedagógicas variava muito apesar de termos mais de 25 professores da rede oficial de ensino cadastrados, que na época não eram liberados para participar dessas oficinas. Quanto aos alunos de Ciências Sociais, o número de participantes oscilava muito também, especialmente no início, quando as oficinas ocorriam durante a semana. Em síntese, à exceção dos alunos bolsistas, tanto alunos da licenciatura como professores da rede oficial não dispunham de muito tempo. Assim, a participação de muitos dos interessados deu-se de forma comprometida e voluntária, o que provocou a necessidade de retomarmos frequentemente alguns dos temas discutidos anteriormente.

As Oficinas Pedagógicas eram, portanto, temáticas. Depois de apresentado o tema, quando da preparação dos conteúdos, fazíamos um levantamento junto com os professores do ensino médio, para definição dos aspectos possíveis de serem trabalhados em sala de aula conforme a realidade de suas escolas. Simultaneamente, os licenciandos, junto com os professores de Sociologia no ensino médio e os docentes da universidade, pensavam em conteúdos, objetivos, metodologia/estratégias e atividades. Para a superação conjunta das diversas dificuldades, foi importante estarmos sempre avaliando a que distância nos 
encontrávamos dos objetivos traçados e/ou a necessidade de caminharmos em outra direção. Por isso tivemos, muitas vezes, de redimensionar o trabalho, estabelecendo prioridades ante os temas desenvolvidos.

O licenciando, mesmo cursando o período noturno, colaborava nessas atividades e, quando possível, participava em reuniōes e minicursos destinados a professores do ensino médio. Assim, as Oficinas Pedagógicas contribuíram tanto para a formação inicial como continuada de professores.

Consolidada a implantação do Laboratório, a partir dos dados obtidos no processo de observação e investigação em sala de aula e produção de material didático, possibilitamos a integração das três instâncias de atividades que são o eixo da universidade: ensino, pesquisa e extensão.

As Oficinas Pedagógicas desenvolvidas nos quase nove anos de existência assessoraram o trabalho de professores da rede de ensino, mas também acompanharam tanto os estágios realizados pelos licenciandos como as monografias de final de curso cujo objeto fosse o ensino de Sociologia no ensino médio. Nesse processo, procuramos ainda discutir como o conhecimento científico, desenvolvido pelas diferentes disciplinas que compunham o currículo do curso de Ciências Sociais, transformava-se em conteúdo escolar, no ensino médio. Para tanto, é importante reiterarmos que a contribuição para a formação do licenciando advinha tanto das disciplinas da área específica como da área pedagógica do curso.

Quanto à formação inicial, as Oficinas Pedagógicas possibilitaram o enfrentamento de um problema muito antigo, que é a integração entre o bacharelado e a licenciatura. Tal experiência minimizou o problema do processo dicotômico entre forma e conteúdo e processo e produto entre as duas modalidades acadêmicas. Conseguiu, assim, dar maior visibilidade à licenciatura ante o esforço de não a considerarmos uma simples complementação do bacharelado, e consequentemente cumprir um importante papel no processo de formação de professores de Sociologia.

A partir de 2006, uma das questôes apontadas pelos alunos dizia respeito à disciplina sob a nossa responsabilidade ${ }^{1}$ - Projeto de Atuação em Ensino III, dada a exigência de realização de 17 horas de estágio para alunos do noturno, na sua maioria trabalhadores. Mas o 
problema maior dizia respeito também à quase ausência da Sociologia no currículo do ensino médio. Por se constituir em uma disciplina do núcleo diversificado naquela época, era encontrada em apenas 23 escolas da região de Campinas. Em relação à formação inicial e continuada, a participação nas Oficinas Pedagógicas mensais oferecidas pelo LESC contribuiu para a troca de experiências dos licenciandos com professores do ensino médio.

Após cada oficina, realizávamos, em sala de aula, com os alunos de Ciências Sociais do $7^{\circ}$ e $8^{\circ}$ semestres, uma avaliação das diferentes experiências que tiveram a oportunidade de vivenciar, no sentido de ampliar a troca entre eles: estágio em salas de aula, estágio no projeto Escola da Família, estágio a partir do oferecimento das oficinas para alunos e professores do ensino médio. As avaliações eram sempre bastante ricas.

Foi a primeira vez que um planejamento de ensino foi colocado em prática. Nas oficinas fizemos com que todos atuassem para ficarmos mais confiantes. (Equipe responsável pelo tema "cidadania", 2006)

É a primeira vez que temos a oportunidade para realizar uma atividade que envolve alunos do $7^{\circ}$ e $8^{\circ}$ semestres. Foi ótimo para o entrosamento e para aprender a trabalhar em equipe. (Aluno de Ciências Sociais do $8^{\circ}$ semestre, 2006)

É importante destacar que enfrentar uma sala de aula é diferente de os alunos virem para a universidade como voluntários. (Aluna de Ciências Sociais do $7^{\circ}$ semestre, com estágio realizado em sala de aula, 2007)

Diante do propósito colocado pelos PCN (1999) de se formar o aluno com vistas às transformações que ocorrem em nível mundial, em especial às mudanças referentes ao mundo do trabalho, víamos, cada vez com mais clareza, a necessidade de o ensino de Sociologia vir a ocupar uma posição privilegiada no currículo. No entanto, a trajetória percorrida por nós foi permeada de momentos de vitórias e momentos de decepçôes.

O desafio maior foi o de oferecer uma formação ao jovem do ensino médio que possibilitasse a reflexão e o desenvolvimento de habilidades de pesquisa que permitissem a comunicação, a criatividade, o saber resolver problemas e trabalhar em equipe. E, ainda, desenvolver no aluno a reflexão crítica que deveria ir muito além do desenvolvimento das capacidades técnicas necessárias para a inserção do futuro profissional no 
mercado de trabalho, principal objetivo da proposta de reforma educacional então em curso.

Nos final dos anos de 1990 e no início do século atual foram comuns questionamentos relacionados à prática de ensino da Sociologia. Havia muitas perguntas sobre o que fazia o sociólogo... Muitos alunos do ensino médio frequentemente perguntavam por que e para que estudavam Sociologia. Em vista desses questionamentos, foi necessário fortalecer junto aos professores os argumentos sobre a importância da Sociologia e realizar constantes debates sobre esta disciplina no ensino médio, uma vez que a questão da hierarquização dos saberes da ciência está muito enraizada também no cotidiano da sala de aula.

Para intensificar a forma de preparação das aulas e a análise da atuação de professores de Sociologia da rede oficial de ensino, optamos, ao longo da experiência, por realizar e discutir relatos de suas experiências em sala de aula. Paralelamente ao esforço despendido por tais docentes, pudemos notar que, embora algumas escolas tivessem optado pela Sociologia na grade curricular, havia uma diferenciação no tratamento dado a esta disciplina em relação às outras consideradas obrigatórias. O pouco tempo destinado à Sociologia contribuía para dificultar ainda mais o seu reconhecimento.

Periodicamente realizávamos avaliações com os professores da rede oficial que participavam das oficinas e os relatos mais frequentes diziam respeito ao sentimento de ser professor, à transformação da prática pedagógica e à atualização dos conteúdos.

Os depoimentos desses professores de Sociologia revelaram, desde o início das Oficinas Pedagógicas, que a grande maioria estava interessada em renovar-se teoricamente e disposta à mudança e à busca de formas alternativas de trabalho pedagógico. Quando perguntamos acerca das expectativas e do que gostariam de discutir nos encontros promovidos pelo LESC, responderam que queriam trabalhar as temáticas propostas pelos Parâmetros Curriculares da área.

As oficinas do LESC influenciaram na minha prática pedagógica na medida em que me colocou novamente em contato com a universidade e consequentemente com as discussōes atuais das Ciências Sociais. Isso aumentou incrivelmente meu estímulo pela Sociologia porque, partilhando experiências com os colegas do LESC e com as professoras (que são o elo entre eu e as discussóes acadêmicas), deixei de sentir-me isolada em 
Sociologia no ensino médio em um mundo em mudanças...

minha prática e pude rever conceitos. Dessa forma, aumentei minha autoestima, que anda baixa entre os professores da rede. (Professora da rede oficial de ensino, 2000)

Sociologia é importante, sim, ela deveria continuar no ensino médio, mas não só no terceiro ano, no primeiro e no segundo ano também. Pois em um só ano é muito corrido para guardar tanta coisa importante. (Professor da rede oficial de ensino, 2004)

Muitos outros depoimentos relevantes foram registrados no decorrer do processo. Ao longo dos nove anos, constatamos que as dificuldades em sala de aula continuavam sendo profundas e muito díspares, e que, apesar das constantes reflexões que realizávamos nas Oficinas Pedagógicas oferecidas pelo LESC, os professores de Sociologia não haviam transformado, como esperávamos, a prática de ensino no cotidiano escolar. Percebíamos alguns estranhamentos didático-pedagógicos, sem muita compreensão do que ocorria com o alcance e a influência dos conceitos trabalhados no processo de formação de professores no Laboratório.

Permaneciam alguns hábitos muito arraigados no momento da revisão de seus planos de ensino, como o uso de materiais didáticos tradicionais e referências bibliográficas de áreas de formação docente diferentes da Sociologia. A reflexão sobre certos temas, teorias e conceitos revelava ambiguidades, fragilidades, inseguranças, práticas limitadoras para o alcance de um projeto político-pedagógico democrático a que se propunha o LESC.

Analisar a realidade social é uma tarefa árdua, mas necessária nas escolas, pois desconstrói noções prematuras e simplórias. Caso contrário, os alunos poderão sair da escola com seus preconceitos ainda mais reforçados, com baixa autoestima, naturalizando ainda mais a situação social em que vivem sem perspectiva para melhorar socialmente sua vida, sua comunidade e seu país. (Camargo, "Proposta de Trabalho", s/d)

Em suma, as experiências vivenciadas tornaram-se difíceis para todos os envolvidos neste processo, uma vez que os docentes e licenciandos sentiam motivação para os encontros mensais e para a partilha de conhecimentos durante as oficinas. No entanto, pouca alteração acontecia no cotidiano da sala de aula das escolas públicas envolvidas, gerando inclusive desânimo entre os licenciandos da Faculdade de Ciências Sociais quanto à escolha da profissão. $\mathrm{O}$ encerramento das atividades do LESC 
em 2007 deu-se por razões de alterações funcionais da coordenação da equipe de docentes responsáveis pela organização das oficinas, mas as indagações permaneceram à espera de revisões para momentos mais oportunos para serem explicitadas.

O contato com os textos de Dagnino $(2004,2005,2006)$ e a compreensão da dimensão da "confluência perversa" posterior à existência do LESC possibilitaram-nos entender melhor o processo vivenciado na formação inicial e continuada de professores a partir das Oficinas Pedagógicas.

\section{A Sociologia, o ensino médio e a questão da "confluência perversa"}

No período de existência do LESC, como indicamos, a educação e a escola passavam por um conjunto de mudanças bastante influenciadas pelo projeto político neoliberal, provavelmente com intensidade maior no Estado de São Paulo, mudanças essas que atingiram as relações de trabalho docente, cada vez mais precarizado, fragmentado e desregulamentado. Ao mesmo tempo, ocorriam a implantação e aperfeiçoamento de avaliaçóes de larga escala com "ranqueamento" entre as escolas, preocupações que passaram a marcar diretamente os conteúdos didático-pedagógicos em função dos resultados públicos dos exames nacionais e estaduais (ENEM e SARESP) para os alunos de ensino médio. E mais, o espaço da escola pública passou a ser disputado ainda por projetos sociais diversos de educação não formal (Lopes, 2009; Lopes \& Oliveira, 2010) pensados por "parcerias" com a sociedade civil (como as ONG), que em nosso entender se tornaram um dos núcleos de atuação da "confluência perversa" no país, pouco percebida naqueles anos de funcionamento do LESC e talvez até nos dias de hoje. A autonomia do docente e do projeto político-pedagógico da escola foram duramente atingidos, uma vez que tais "parcerias" e "serviços" sociais quase sempre não são submetidos a uma discussão democrática interna da comunidade escolar envolvida para a aprovação de critérios e de conteúdos que se adequem à realidade concreta da escola. ${ }^{2}$

Na reforma de ensino brasileira, a diretriz de privatização da educação não assumiu o formato de transferência direta de serviços públicos ao setor privado porque a Constituição de 1988 estabeleceu que o ensino público seria gratuito em todos os níveis (...). A privatização, entretanto, vem 
Sociologia no ensino médio em um mundo em mudanças...

ocorrendo por um mecanismo indireto, que é a constituição do mercado de consumo de serviços educacionais privados. (Pierro, 2001, p. 326)

Conceitos clássicos tornam-se cada vez menos históricos, como o de cidadania e participação, deslocando-se para definições como "ajuda ao próximo", "voluntariado", "empreendedorismo", "direitos do consumidor", "responsabilidade social" (Paoli, 2003a), em conhecidos projetos que estão atuando nas escolas por meio de "parcerias" do setor público com o setor privado.

Na década de 1990 e no início dos anos de 2000, a experiência democrática de base popular, mesmo existindo de forma subalterna, construída na década de 1980, fazia-se presente em nossos referenciais teóricos e metodológicos, seja nas Ciências Sociais, seja na educação. Período histórico em que Paoli (2003b, p. 184) aponta como sendo "o único período em que se delineia a constituição política, com base popular, de uma real experiência de cidadania e formação de espaços públicos e sujeitos coletivos discerníveis na cena pública”.

$\mathrm{O}$ que não tínhamos noção naquele momento era sobre a extensa penetração que as concepçóes neoliberais estavam operando em todos os níveis da sociedade brasileira, e com igual influência em todos os níveis educacionais, por meio da hegemonia da racionalidade técnica (Costa, 2009). Momento em que se dava uma "estratégia do Estado para a implementação do ajuste neoliberal (...) que se isenta progressivamente de seu papel garantidor de direitos (...)" (Dagnino, 2004, p. 96).

Enfrentávamos no período de trabalho do LESC uma "crise discursiva” para pensarmos as relaçôes entre realidade social, ciência e conhecimento escolar para a Sociologia do ensino médio. $\mathrm{Na}$ verdade estávamos no centro de várias ambiguidades que se explicitavam nas dificuldades de abordagem de conteúdos nas Oficinas Pedagógicas. $\mathrm{Na}$ prática, certos planos de aula podiam atender a um ou outro "projeto político" que, conforme define Dagnino (2004; 2005), inspirada em Gramsci, é um conjunto de crenças, interesses, representações do que deve ser a vida em sociedade, orientando a ação política de diferentes sujeitos sociais, em que cultura e política são processos indissociáveis.

Vivenciamos desde então, de um lado, a cultura política do projeto democrático participativo, forjada nas experiências dos novos movimentos sociais e de redemocratização do país. A produção intelectual 
da educação debatia intensamente temas como o de conquistar a gestão democrática participativa da escola, para mencionar um exemplo. De outro lado, a cultura política do projeto neoliberal, que passa a se apropriar daquela cultura, re-significando concepções caras ao pensamento crítico e social do país, que incluíam reconhecidos projetos educacionais emancipatórios.

Entendemos neste momento que a tendência em curso é a de que o trabalho docente no ensino médio tem sido pressionado a tratar os conceitos com sentidos cada vez mais restritos, imediatistas, para atender a formação para o trabalho e para o mercado.

A Sociologia também foi e é pressionada a se adaptar ao projeto neoliberal voltado para a educação. O balanço crítico que temos oportunidade de realizar neste momento sobre o LESC influencia na análise do que supomos estar ocorrendo com os Cadernos de Sociologia para o ensino médio.

A proposta curricular do estado de São Paulo prevê o desenvolvimento de um conjunto de conteúdos programáticos nos Cadernos de Sociologia do Professor e do Aluno. Afirma serem esses cadernos norteadores das disciplinas a serem ministradas e que têm o objetivo de criar uma base curricular que não prejudique as características locais de um estado tão grande e diverso.

No que cabe ao professor de Sociologia, esses Cadernos foram solicitados e escritos seguindo as orientações de uma das mais representativas entidades dos sociólogos, a Sociedade Brasileira de Sociologia (SBS), que tem estado cada vez mais à frente destas discussões ${ }^{3}$ Esta entidade discute temas relativos ao ensino de Sociologia no ensino médio desde o período em que participou da luta pela inclusão obrigatória da disciplina no ensino médio.

Eles [Cadernos] foram um desafio, entre outras razões, pois tive a responsabilidade de concretizar a Proposta Curricular para o Ensino de Sociologia que foi elaborada pela Sociedade Brasileira de Sociologia e aceita pela Secretaria Estadual de Educação. (Schrijnemaekers, 2009, p. 3)

Em trabalho apresentado XIV Congresso Brasileiro de Sociologia, o grupo de trabalho "Ensino de Sociologia", representado por Schrijnemaekers, expôs sobre o processo de construção de tal material 
por meio do artigo "O ensino de Sociologia e a escola pública: desafios" (2009). A autora demonstra que a construção do Caderno de Sociologia foi e é um grande desafio, tendo em vista a complexidade da disciplina e a carga horária reservada à Sociologia no ensino médio, entre outros limites já indicados anteriormente. Schrijnemaekers (2009) afirmou ter escrito o material de maneira conjunta com Melissa de Mattos Pimenta, entre outros colaboradores, todos sob coordenação da professora Heloisa de Souza Martins. ${ }^{4}$

Em nossa compreensão, a criação e a utilização desses Cadernos é uma proposta da Secretaria de Educação do estado e visa sugerir um roteiro de trabalho, logo, na sua criação, por autoras como Schrijnemaekers, Pimenta e Martins, não se pensou em criar modelos e/ou uma apostila de Sociologia a ser seguida de maneira engessada. Nesta proposta curricular de Sociologia, representada pelo grupo de trabalho da SBS, há um compromisso com a ideia de que é possível, por via da construção processual e coletiva do conhecimento, uma reflexão crítica da realidade. Para tanto a divisão dos Cadernos foi feita em três grandes eixos do conhecimento articulados no decorrer dos três anos do ensino médio; são estes: o que é Sociologia e como se constrói um olhar sociológico; o Brasil e as diversidades; questôes relativas à cidadania. ${ }^{5}$

Segundo Schrijnemaekers (2009), o material foi encadeado de maneira que, com o passar dos anos, fique mais complexo e, por conseguinte, possibilite ao aluno o aprendizado a partir do lúdico (primeiro ano), de pesquisas mais consistente sobre temas do bimestre (segundo ano) e da discussão teórica mais aprofundada (terceiro ano). A preocupação na construção deste material foi pensada para ser relacionada à realidade encontrada e a todo o momento se buscava não se caracterizar como um instrumento impossível de ser utilizado por sua complexidade ou simples demais perante a importância da Sociologia. Contudo, tal preocupação parece não bastar para garantir que sua utilização pela escola tenha seus objetivos alcançados, pois, como vimos, a escola passa por problemas estruturais e enfrenta a hegemonia da racionalidade técnica em seu interior.

No que foi possível observar no contato com docentes ${ }^{6}$ de Sociologia do ensino médio da rede pública, na prática tais Cadernos, por vezes, são transformados em cartilhas, apostilas a serem seguidas 
à risca, uma vez que, entregue o material que é composto também por exercícios, a tendência é pedir ao aluno que concentre a atenção para dar respostas mecânicas e não para a reflexão da temática abordada. Os conteúdos estão condicionados pelas avaliações do ensino médio (SARESP) e devem estar na ponta da língua dos alunos para se conseguir "boa colocação" no "ranqueamento" existente e, por consequência, bonificaçôes para a escola, sobretudo bônus salarial.

Essas situações fazem com que temas tão importantes da Sociologia sejam trabalhados de forma a-histórica e teoricamente descontextualizados. Muitas dessas situações podem ser atribuídas ao projeto de racionalidade instrumental que prioriza mudanças quantitativas e incentiva o crescimento individual, a competição para o mercado de trabalho, e não o bem da coletividade, a vida em sociedade. Estas são algumas das situações que não estavam claras na experiência do LESC e que estão sendo enfrentadas em outras realidades mais amplas e oficiais nos sistemas da rede de ensino.

Diante destes desafios, a especificidade do ensino de Sociologia pode estar na decisão de se inserir em uma agenda político-cultural (Dagnino, 2005), com a explicitação mais concreta de conflitos e de interesses que a "confluência perversa" obscurece. A tarefa sociológica clássica de desnaturalização dos preconceitos e estereótipos sociais passa por uma urgente e renovada desnaturalização dos próprios conceitos, como os de cidadania, sociedade civil e participação (ressignificados desde a expansão nacional e internacional da economia global) para superar as ambiguidades dos discursos que permeiam a sala de aula e a educação.

Concordando com Dagnino (2004), é preciso reafirmar a importância da "política", desta vez para repensar tanto o processo de formação inicial como a continuada de professores, uma vez que objetivamos a defesa do projeto democrático participativo e a cidadania ampliada também no ensino de Sociologia.

\section{Notas}

1. Professora doutora Dulce Maria Pompêo de Camargo.

2. Ver, por exemplo: Programa Aprendiz COMGÁs (disponível em: <http://www. aprendizcomgas.com.br/>); Amigos da Escola - Todos pela Educação (disponível em: 
Sociologia no ensino médio em um mundo em mudanças...

$<$ http://amigosdaescola.globo.com/>); Instituto Ayrton Senna - Superação Jovem (disponível em: <http://senna.globo.com/institutoayrtonsenna/novo_site/home/index.asp>).

3. A Comissão de Ensino da Sociedade Brasileira de Sociologia (sBs) conta, em nível estadual, com a participação de docentes da UNESP, UNICAMP, USP e UNIFESP que trabalham nas licenciaturas do Curso de Ciências Sociais. O I Encontro Estadual foi realizado em outubro de 2010 na USP e, em julho de 2011, foi realizado o II Encontro Nacional sobre o Ensino de Sociologia, que teve uma participação importante do estado de São Paulo. A Secretaria Estadual de Educação atendeu a solicitação da Comissão Organizadora e autorizou os professores de Sociologia da rede pública estadual a participarem.

4. Artigo disponível em: <http://starline.dnsalias.com:8080/sbs/arquivos/16_6_2009_8_ $12 \_40 . p d f>$.

5. Ver orientações no Programa "São Paulo Faz Escola", disponível em: <http://www. rededosaber.sp.gov.br/portais/Portals/18/arquivos/PPC_soc_revisado.pdf>.

6. Com alguns alunos egressos ou estagiários de licenciatura do Curso de Ciências Sociais da PUC-Campinas e docentes participantes do então LESC.

\section{Referências}

BRASIL. Lei n. 11.684, de 02 de junho de 2008. Altera o art. 36 da lei 9.394, de 20 de dezembro de 1996, que estabelece as diretrizes e bases da educação nacional, para incluir a filosofia e a sociologia como diciplinas obrigatórias nos currículos do ensino médio. Diário Oficial da Uniāo, Brasília, DF, 03/06/2008. p. 1. Disponível em: http://www. planalto.gov.br/ccivil/_Ato20072010/2008/Lei/L11684.htm\#art1 Acesso em: 13 jun. 2009.

BUENO, M.S.S. Politicas atuais para o ensino médio. Campinas: Papirus, 2000.

CAMARGO, D.M.P. Projeto de Pesquisa e Extensão "Laboratório de Ensino, Sociedade e Cultura", aprovado pela PUC-Campinas, 1997.

CAMARGO, D.M.P. Conhecimento escolar: o mito da fronteira entre a ciência e a cultura. In: Veiga, I.; Castanho, M.E. (Org.). Pedagogia universitária: a aula em foco. Campinas: Papirus, 2000. p. 213230.

COHN, G. A sociologia como interrogação. In: BARReira, C. (Org.). A sociologia no tempo: memória, imaginação e utopia. São Paulo: Cortez, 2003. p. 83-87. 
COSTA, R.F. Formação inicial de professores de sociologia: uma análise de suas necessidades formativas. 2009. Dissertação (Mestrado em Educação) - Pontifícia Universidade Católica de Campinas, Campinas.

DAGNINO, E. Sociedade civil, participação e cidadania: de que estamos falando? In: Mato, D. (Coord.). Politicas de ciudadanía y sociedad civil em tiempos de globalización. Caracas: FACES, Universidad Central de Venezuela, 2004. p. 95-110. Disponível em: <http:// bibliotecavirtual.clacso.org.ar/ar/libros/venezuela/faces/mato/ Dagnino.pdf $>$.

DAGNINO, E. Políticas culturais, democracia e o projeto neoliberal. Revista Rio de Janeiro, Rio de Janeiro, n. 15, p. 45-65, jan./abr. 2005. Disponível em: <http://www.forumrio.uerj.br/documentos/revista_ 15/15_dossie_EvelinaDagnino.pdf $>$.

DAGNinO, E.; OlverA, A.J.; PANFICHI, A. (Org.). A disputa pela construção democrática na América Latina. São Paulo: Paz \& Terra; Campinas: Unicamp, 2006.

IANNI, O. Tendências do pensamento brasileiro. Tempo Social, São Paulo, v. 12, n. 2, p. 55-74, nov. 2000.

O INCHAÇO do currículo escolar. O Estado de S. Paulo, São Paulo, 20 ago. 2010, Notas e informações, Caderno A, p. 3.

LORDELO, C. Ensino médio não prepara aluno para o mercado, diz empresário. O Estado de S. Paulo, São Paulo, 18 ago. 2011. Disponível em: < http://www.estadao.com.br/noticias/vidae,ensino-medionao-prepara-aluno-para-o-mercado-diz-empresario,760447,0.htm > Acesso em: 15 set. 2011.

LOPES, D.A. Sociologia e PLC 9/00: o fim do imponderável. Correio Popular, Campinas, 8 set. 2001.

LOPES, D.A. Educação não formal e avaliação: em busca de um debate. In: SIMPÓSIO INTERNACIONAL O ESTADO E AS POLÍTICAS EDUCACIONAIS NO TEMPO PRESENTE, 5., 2009, Uberlândia. Anais... Uberlândia: Programa de Pós-Graduação em Educação, Universidade Federal de Uberlândia, 2009. Disponível em: $<$ http://www.simposioestadopoliticas.ufu.br/anais/001-integra.doc>. 
LOPES, D.A.; OLIVEIRA, L.S. Movimentos sociais e a ambiguidade do conceito de educação não formal. Revista Iberoamericana de Educación, Madrid, n. 53/54, 2010. Disponível em: <http://www. rieoei.org/deloslectores/3790Silva.pdf $>$.

MORAES, C.S.V. Ensino médio e qualificação profissional: uma perspectiva histórica. In: BRUNO, L. Educação e trabalho no capitalismo contemporâneo: leituras selecionadas. São Paulo: Atlas, 1996. p. 124-145.

PAOLI, M.C. Empresas e responsabilidade social: os enredamentos da cidadania no Brasil. In: SANTos, B.S. (Org.). Democratizar a democracia: os caminhos da democracia participativa. 2. ed. Rio de Janeiro: Civilização Brasileira, 2003a. p. 373-418.

PAOLI, M.C. Movimentos sociais, movimentos republicanos? In: SILVA, F.T et al. (Org.). República, liberalismo, cidadania. Piracicaba: UNIMEP, 2003b. p. 163-189.

PIERRO, M.C. Descentralização, focalização e parceria: uma análise das tendências nas políticas públicas de educação de jovens e adultos. Educação \& Pesquisa, São Paulo, v. 27, n. 2, p. 321-337, jul./ dez. 2001. Disponível em: <http://www.scielo.br/pdf/ep/v27n2/ a09v27n2.pdf>.

SCHRIJNEMAEKERS, S.C. O ensino de Sociologia e a escola pública: desafios. In: CONGRESSO BRASILEIRO DE SOCIOLOGIA, 14., 2009, Rio de Janeiro. Anais... Rio de Janeiro: SBS, 2009. Disponível em: <http://starline.dnsalias.com:8080/sbs/arquivos/16_6_2009_ 8_12_40.pdf>.

Recebido em 3 de novembro de 2010

Aprovado em 22 de setembro de 2011 